\title{
In vitro antioxidant and, a-glucosidase inhibitory activities and comprehensive metabolite profiling of methanol extract and its fractions from Clinacanthus nutans
}

Md. Ariful Alam', I.S.M. Zaidul ${ }^{1 *}$, Kashif Ghafoor², F. Sahena ${ }^{3}$, M. A. Hakim ${ }^{4}$, M.Y. Rafii ${ }^{4}$, H.M. Abir ${ }^{5}$, M.F. Bostanudin' $\checkmark$ Perumal ${ }^{1}$ and $A$. Khatib ${ }^{1}$

\begin{abstract}
Background: This study was aimed to evaluate antioxidant and a-glucosidase inhibitory activity, with a subsequent analysis of total phenolic and total flavonoid content of methanol extract and its derived fractions from Clinacanthus nutans accompanied by comprehensive phytochemical profiling.

Methods: Liquid-liquid partition chromatography was used to separate methanolic extract to get hexane, ethyl acetate, butanol and residual aqueous fractions. The total antioxidant activity was determined by 2,2-diphenyl-1-picrylhydrazy (DPPH) radical scavenging and ferric reducing antioxidant power assay (FRAP). The antidiabetic activity of methanol extract and its consequent fractions were examined by a-glucosidase inhibitory bioassay. The chemical profiling was carried out by gas chromatography coupled with quadrupole time-of-flight mass spectrometry (GC Q-TOF MS).

Results: The total yield for methanol extraction was $(12.63 \pm 0.98) \%(W / W)$ and highest fractionated value found for residual aqueous $(52.25 \pm 1.01) \%(\mathrm{~W} / \mathrm{W})$ as compared to the other fractions. Significant DPPH free radical scavenging activity was found for methanolic extract $(63.07 \pm 0.11) \%$ and $(79.98 \pm 0.31) \%$ for ethyl acetate fraction among all the fractions evaluated. Methanol extract was the most prominent in case of FRAP (141.89 $\pm 0.87 \mu \mathrm{g} \mathrm{AAE} / \mathrm{g})$ whereas most effective reducing power observed in ethyl acetate fraction $(133.6 \pm 0.2987 \mu \mathrm{g} \mathrm{AAE} / \mathrm{g})$. The results also indicated a substantial a-glucosidase inhibitory activity for butanol fraction (72.16 \pm 1.0$) \%$ and ethyl acetate fraction $(70.76 \pm 0.49) \%$. The statistical analysis revealed that total phenolic and total flavonoid content of the samples had the significant $(p<0.05)$ impact on DPPH free radical scavenging and a-glucosidase inhibitory activity.

Conclusion: Current results proposed the therapeutic potential of Clinacanthus nutans, especially ethyl acetate and butanol fraction as chemotherapeutic agent against oxidative related cellular damages and control the postprandial hyperglycemia. The phytochemical investigation showed the existence of active constituents in Clinacanthus nutans extract and fractions.
\end{abstract}

Keywords: Clinacanthus nutans, Antioxidant activity, a-glucosidase inhibitory activity, Reducing power, Total phenolic, Total flavonoid, Activity phytochemical profiling

\footnotetext{
* Correspondence: zaidul@iium.edu.my

${ }^{1}$ Faculty of Pharmacy, International Islamic University Malaysia (IIUM), Kuantan

Campus, 25200 Kuantan, Pahang, Malaysia

Full list of author information is available at the end of the article
} 


\section{Background}

The chemotherapeutic uses of medicinal plants are a result of ancient people's belief in their protective effects. Many plants have abundant active secondary metabolites that exhibit certain pharmacological effects in humans. Thus plant based traditional remedies have been developed from these chemotherapeutic agents to prevent certain ailments [1]. These active constituents are varied in their chemical structure, chemical composition, protective activity, and mode of action, hence, medicinal herbs have been used in traditional medicine. Antioxidant-rich natural products in the form of herbal formulations are able to interrupt cellular damage, mainly through the mechanism of free radical scavenging $[2,3]$. Free radical causes oxidative stress related-complications in the human body owing to a physiological imbalance of free radicals and antioxidants, which is related to the impairment of primary metabolites, and consequently result in a number of health impediments $[4,5]$. Phenolic and flavonoid compounds are the most common antioxidant metabolites in plants and include saponins, alkaloids, coumarins, tannins, lignin, terpenoids, stilbenes, quinones, amines and betalains $[6,7]$. These compounds are important active natural products, which possess various biological actions, such as anti-diabetic, anti-inflammatory, hepatoprotective, antiallergic, anti-carcinogenic, anti-thrombotic, anti-microbial activities, anti-atherosclerotic, anti-tumor and anti-mutagenic activity $[8,9]$.

Diabetes is a pandemic endocrine disorder characterized by hyperglycemia resulting from insulin resistance or overall insulin dysfunction [10, 11]. Modern synthetic hypoglycemic agents can cause side effects, are costly and decline in efficiency with long term uses [12, 13]. The inhibition of the $\alpha$-glucosidase enzyme can control the intestinal carbohydrate metabolism by retarding the cleavage of polysaccharides to glucose $[14,15]$. Therefore, the best strategy is to reduce the postprandial upsurge of blood glucose level and prevent late diabetic complications. Thus natural product based $\alpha$-glucosidase inhibitors are the key targets to identify new compounds for the therapeutic management of diabetes [16]. The extensive literature reported more than four hundred natural products isolated from various herbal plants that exhibited digestive enzyme inhibitory activity [17], a majority of the compounds were flavonoid, terpene, and phenylpropanoid ring containing compounds [17].

Clinacanthus nutans Lindau is a medicinal plant from Acantheceae family widely distributed throughout tropical Asia. For a long time, this shrub has been used to prevent skin infections, insect bites and lesions caused by the herpes simplex and varicella-zoster viruses [18, 19]. Many beneficial effects of this plant have been reported, including antidiabetic, antioxidant, anti-proliferative, immunomodulatory, wound healing, anti-inflammatory, analgesic activities and anti-viral activities [20-23]. However, its efficacy is yet to be proven scientifically and more research needs to be carried out, especially with regard to the antidiabetic effects of this plant. Our analysis of the current literature ascertained thatthe free radical scavenging activity, ferric reducing antioxidant power, and $\alpha$-glucosidase inhibitory activity of the methanol extract and its different polar, non-polar fractions from $C$. nutans have not been previously determined. Moreover, the complete phytochemical profile of this plant remains unestablished. Therefore, this study aimed to investigate the in vitro antioxidant and $\alpha$-glucosidase inhibitory activities of methanol extract and its different fractions from C. nutans. Our research also identified the various chemical constituents of the extract and fractions by GC Q-TOF MS, in addition to bioactivity correlation.

\section{Methods}

\section{Sample collection and preparation}

The stem of $C$. nutans was obtained from TKC Herbal Nursery SDN BHD, Pusat Pertanian Pantai Baru, Pantai Negeri Sembilan, Malaysia in September 2014. The plant material was identified by Dr. Alfi Khatib, Associate Professor, Department of Pharmaceutical Chemistry, International Islamic University, Kuantan, Pahang, Malaysia. A voucher specimen (PIIUM 0238-1) was deposited in the herbarium of the Faculty of Pharmacy, International Islamic University, Kuantan, Pahang, Malaysia. The C. nutans stem was dried, in an airy place under shade. When dry the samples were ground in a cutting mill (FRITSCH, Pulverisette 19, Germany), sieved, and fractionated by a vibratory sieve shaker (AS 700, BASIC, RETSCH, Germany) to obtain fine particles. The extracts and fractions were freeze dried before analysis of the pharmacological activity and chemical profile (Alpha 1-2 LD plus CHRIST, Freeze dryer, UK).

\section{Chemicals}

Ethanol (99.5\%, analytical grade), Folin-Ciocalteu phenol reagent, potassium acetate, aluminum chloride, sodium carbonate, methanol, hexane, ethyl acetate and butanol were obtained from Merck Germany (Darmstadt, Germany). $\alpha$ Glucosidase enzyme (Saccharomyces cerevisiae) and 4nitrophenyl $\beta$-D-glucopyranoside substrate were obtained from the Sigma Chemical Co (St. Louis, Mo., U. S. A.). 2, 2Diphenyl-1-picrylhydrazyl (DPPH), methoxyamine hydrochloride, pyridine, $N$-Methyl-N-(trimethylsilyl) trifluoroacetamide, quercetin ( $\geq 95 \%$ HPLC, solid), and rutin hydrate ( $\geq 94 \%$ HPLC, powder) were obtained from Malaysia Sigma-Aldrich (M), Sdn. Bhd. Kuala Lumpur, Malaysia. All other chemicals used were of analytical grade.

\section{Extraction and fractionation}

The solvent extraction of the air-dried stem of $C$. nutans was performed by maceration technique using methanol as the initial solvent in an Erlenmeyer flask. After maceration, 
the mixture was sonicated for $15 \mathrm{~min}$, and set aside for $24 \mathrm{~h}$, filtered, and evaporated in a rotary evaporator at $40^{\circ}$ $\mathrm{C}$ under reduced pressure. The extract was freeze dried and stored ready for pharmacological analysis and fractionation.

The fractionation of dried methanolic extract was achieved by liquid-liquid partition chromatography in a separating funnel using hexane, methanol, and water (13:2:5) with a final volume of $2 \mathrm{~L}$, based on the amount of extract. After vigorous shaking, the mixture was set aside until two layers were formed. To obtain the hexane fraction, the was separated and then concentrated in rotary evaporator at $40{ }^{\circ} \mathrm{C}$ under reduced pressure. To obtain the ethyl acetate fraction, the remaining fraction in the separating funnel was added to ethyl acetate and the evaporation procedure was repeated. Similarly, butanol was added to obtain the butanol fraction; the remaining material in the separating funnel was considered as the residual aqueous fraction. The residual solvent was removed from the extract and fractions by freeze drying. The methanol extract and its four fractions were then freeze-dried and stored at $-80{ }^{\circ} \mathrm{C}$ freezer until use.

\section{Total phenolic content}

The total phenolic content (TPC) of the methanol extract and the derived fractions from $C$. nutans were determined spectrophotometrically according to the Folin-Ciocalteu method [24]. The reaction mixture was prepared by mixing $20 \mu \mathrm{L}$ of the extract solution (at $5 \mathrm{mg} / \mathrm{mL}$ in DMSO), $100 \mu \mathrm{L}$ Folin-Ciocalteu reagent $(1 \mathrm{~mL}$ of Folin-Ciocalteu reagent in $9 \mathrm{~mL}$ of distilled water) and $80 \mu \mathrm{L} \mathrm{7.5 \%} \mathrm{Na}_{2} \mathrm{CO}_{3}$ solution in deionized water. The solution was incubated for 30 min in a dark place at $26.8^{\circ} \mathrm{C}$ and the absorbance was measured at $765 \mathrm{~nm}$. The total phenolic concentration was calculated from a gallic acid (GA) calibration curve 10$100 \mathrm{mg} / \mathrm{L} ; y=0.0005 x+0.0779, \mathrm{R}^{2}=0.9943$. Data were expressed as gallic acid equivalent/g of extract averaged from three measurements.

\section{Total flavonoid content}

The total flavonoid content (TFC) of the C. nutans extract and fractions were estimated according to the aluminum chloride spectrophotometric method based on the formation of aluminum-flavonoid complexes [25]. To prepare the reaction solutions, approximately $2 \mathrm{~mL}$ extract solution ( $0.3 \mathrm{mg}$ in $1 \mathrm{~mL}$ of methanol), $0.1 \mathrm{~mL}$ aluminum chloride hexahydrate solution ( $10 \%$ aqueous $\mathrm{AlCl}_{3}$ solution), $0.1 \mathrm{~mL}$ $1 \mathrm{M}$ potassium acetate and $2.8 \mathrm{~mL}$ of deionized water were mixed together. The mixture was shaken and incubated at $26.8{ }^{\circ} \mathrm{C}$ for $10 \mathrm{~min}$. After incubation, the solution was subjected to spectral analysis at $415 \mathrm{~nm}$. A standard curve was constructed of the absorbance of rutin between 0.005 and $0.1 \mathrm{mg} / \mathrm{mL}$ and the total flavonoid content calculated as mg rutin equivalent per $g$ dry extract. The absorbance at $415 n m=14.171 x+0.0461, \mathrm{R}^{2}=0.9991$.

\section{DPPH free radical scavenging activity}

The free radical scavenging capacity of the methanol extract and each derived fractions from $C$. nutans were analyzed by using a 96-well microplate and 2, 2-diphenyl-1-picrylhydrazyl (DPPH) as the free radical source [26]. For sample preparation, $5 \mathrm{mg}$ freeze dried sample was added to $1 \mathrm{~mL}$ of DMSO, which was vortexed and sonicated to produce a homogenized solution. The sample solution was transferred $(100 \mu \mathrm{L})$ to a $96 w e l l$ plate and $50 \mu \mathrm{L}$ of this sample was diluted with $50 \mu \mathrm{L}$ DMSO. Then, $100 \mu \mathrm{L} \mathrm{DPPH}(5.9 \mathrm{mg}$ in $100 \mathrm{~mL} \mathrm{100 \%} \mathrm{ethanol)} \mathrm{was} \mathrm{added} \mathrm{to} \mathrm{each} \mathrm{of} \mathrm{dilutions,} \mathrm{sus-}$ pended and incubated in a dark place for $30 \mathrm{~min}$. Blank samples were prepared following the same procedure, but used using $100 \mu \mathrm{L} 100 \%$ ethanol instead of DPPH. A reagent blank which contained $50 \mu \mathrm{L}$ DMSO and $100 \mu \mathrm{L}$ $\mathrm{DPPH}$, but no sample was, also subjected to the sample preparation process. Quercetin was used as a positive control to observe the reaction of inhibition. The absorbance was recorded at $517 \mathrm{~nm}$ and the percentage inhibition was calculated by using the following equation-

$$
\text { \%Inhibition }=\frac{R_{b}-\left(S_{a}-B S_{a}\right)}{R_{b}} \times 100
$$

$R_{b}=$ Reagent blank absorbance

$S_{a}=$ Sample absorbance

$B S_{a}=$ Blank sample absorbance

\section{Ferric reducing antioxidant power assay}

The total antioxidant capacity of methanol extract and other derived fractions were examined by using the FRAP method adapted by Szd lowska Czerniak et al., with some modifications [27]. FRAP reagent $(10 \mathrm{mM}$ TPTZ solution) $(2.5 \mathrm{~mL})$ in $40 \mathrm{mM} \mathrm{HCl}, 20 \mathrm{mM} \mathrm{FeCl}_{3}$ $(2.5 \mathrm{~mL})$, and $0.1 \mathrm{M}$ acetate buffer $\mathrm{pH} 3.6(25 \mathrm{~mL})$ was freshly prepared and incubated for $10 \mathrm{~min}$ at $37{ }^{\circ} \mathrm{C}$ in an oven. Then $20 \mu \mathrm{L}$ of different concentration $(0 \%, 20 \%$, $40 \%, 60 \%, 80 \%$ and $100 \%$ ) of methanol extract and fractions of $C$. nutans and ascorbic acid (standard) and $40 \mu \mathrm{L}$ FRAP reagent were added to $140 \mu \mathrm{L}$ of distilled water in a 96 wells plate. The samples were stored at $26.8{ }^{\circ} \mathrm{C}$ for $20 \mathrm{~min}$ in dark and the blue color was quantified through measurement of the absorbance at $593 \mathrm{~nm}$ relative to a reagent blank ( $40 \mu \mathrm{L}$ FRAP reagents and $160 \mu \mathrm{L}$ distilled water) using microplate reader. Ascorbic acid was used as a standard compound to create a calibration curve. The total antioxidant capacity of the samples was expressed in ascorbic acid equivalents as (AAE) in $\mu \mathrm{g} /$ $\mathrm{g}$ of dried sample.

\section{a-Glucosidase inhibitory assay}

The $\alpha$-glucosidase inhibitory activity of the C. nutans extract and each of the fractions from liquid-liquid partition chromatography was determined following the method by 
Collins et al., [28]. In this assay, the formation of $p$-nitrophenol that resulted from the cleavage of $p$-nitrophenyl- $\alpha$ D-glucopyranose was estimated for the evaluation of $\alpha$ glucosidase inhibitory activity. To prepare the stock solution, $5 \mathrm{mg}$ of the extract and fractions were dissolved in $1 \mathrm{~mL}$ of DMSO. Additionally, $5 \mathrm{mg}$ quercetin was dissolved in $1 \mathrm{~mL}$ of DMSO to form a positive control [29]. For the dilution, $10 \mu \mathrm{L}$ prepared stock solutions were added to $115 \mu \mathrm{L} 30 \mathrm{mM}$ phosphate buffer ( $\mathrm{pH}$ 6.5). The enzyme ( $\alpha$-glucosidase type 1 from Saccharomyces cerevisiae) (Sigma G5003) solution was prepared using $1 \mathrm{mg}$ enzyme with $13.9 \mathrm{~mL} 50 \mathrm{mM}$ phosphate buffer ( $\mathrm{pH} 6.5$ ). The substrate containing $3 \mathrm{mg} p$-nitrophenyl- $\alpha$ - Dglucopyranose (Sigma-Aldrich, N1377-1G) was dissolved in $10 \mathrm{~mL}$ of a $50 \mathrm{mM}$ phosphate buffer (pH 6.5) and incubated at $26.8{ }^{\circ} \mathrm{C}$ for $15 \mathrm{~min}$. The diluted samples were mixed with $15 \mu \mathrm{L}$ of enzyme and $75 \mu \mathrm{L}$ of substrate in the microplate, and incubated for $15 \mathrm{~min}$ at $26.8^{\circ} \mathrm{C}$. A blank sample, positive control, negative control, and blank positive control were prepared according to the mentioned method. Glycine solution was prepared as a reactionstopping reagent by the dissolution of $15 \mathrm{~g}$ with $100 \mathrm{~mL}$ of cold water ( $\mathrm{pH} 10)$. The optical densities (ODs) were read at $405 \mathrm{~nm}$ in a multi-detection micro-plate reader (Infinite M200, Tecan, Switzerland) [30]. The inhibitory activity was calculated according to the following equation

$$
\text { \%Inhibition of sample }=\frac{a_{n}-a_{s}}{a_{n}} \times 100
$$

where $a_{n}=$ negative control and $a_{p}=$ (Sample AbsorbanceBlank Sample Absorbance).

\section{Derivatization for GC Q-TOF MS analysis}

Derivatization of the methanol extract and the derived polar-nonpolar fractions from $C$. nutans were performed by methoxyamination and trimethylsilylation (TMS) for GC Q-TOF MS chemical profiling according to the method mentioned by Robinson et al. [31]. The methoxyamine hydrochloride was dissolved in pyridine to produce a concentration of $20 \mathrm{mg} / \mathrm{mL}$. Exactly $2.5 \mathrm{mg}$ of sample was mixed with $50 \mu \mathrm{L}$ pyridine in a $2-\mathrm{mL}$ centrifuge tube and sonicated for $10 \mathrm{~min}$ at $30{ }^{\circ} \mathrm{C}$. Then, $100 \mu \mathrm{L}$ methoxyamine hydrochloride $(20 \mathrm{mg} / \mathrm{mL}$ in pyridine) was added to the sample solution and incubated for $2 \mathrm{~h}$ at $60^{\circ}$ C. After the incubation $300 \mu \mathrm{L}$ MSTFA ( $N$-Methyl- $N$-(trimethylsilyl) trifluoroacetamide) was mixed and incubated for a further $30 \mathrm{~min}$ at $60{ }^{\circ} \mathrm{C}$. The prepared sample was stored overnight at $23{ }^{\circ} \mathrm{C}$ for the completion of chemical reaction. The mixture was then filtered by syringe filter for the separation of any solid particles.

\section{GC Q-TOF MS determination}

The GC-MS Agilent system of model 7200 accurate-mass GC QTOF equipped with a 7890A GC system connected to a detector quadrupole time of flight mass spectrometer was used to acquire mass spectral data. Exactly, $1 \mu \mathrm{L}$ of derivatized sample was injected into the inlet of the Agilent GC column (J \&W Scientific, Folsom, CA, USA) model, HP-5MS; dimensions $30 \mathrm{~m} \times 0.25 \mathrm{~mm} \times 0.25 \mu \mathrm{m}$ ), with 50:1 split mode and ratio. The injector temperature was maintained at $280{ }^{\circ} \mathrm{C}$ and the detector was maintained at $290{ }^{\circ} \mathrm{C}$. The oven temperature profile was as follows: an increase from set to 70 to $135{ }^{\circ} \mathrm{C}$ with a $2{ }^{\circ} \mathrm{C} / \mathrm{min}$, hold for $10 \mathrm{~min}$, an increase from 135 to $220^{\circ} \mathrm{C}$ with $4{ }^{\circ} \mathrm{C} / \mathrm{min}$, hold for $10 \mathrm{~min}$, an increase from 220 to $270{ }^{\circ} \mathrm{C}$ at $3.5^{\circ} \mathrm{C} / \mathrm{min}$ and then a final hold for $20 \mathrm{~min}$. Helium was used as carrier gas at a constant flow rate of $1.9 \mathrm{~mL} / \mathrm{min}$. GC Q-TOF MS, and Auto MS-MS data were processed with Mass Hunter qualitative analysis software (v. B.06.00 SP1, Agilent Technologies Inc., USA). Agilent Mass Profiler Professional (MPP) software was used to eliminate the molecular features produce from background by deduction of data from the blank spectrum. The mass spectral deconvolution was performed by Mass Hunter Unknown Analysis Software (version B.06.00) which automatically detected peaks and deconvoluted the spectra using model ion traces.

\section{Statistical analysis}

The results were calculated as the mean \pm SD from three separate experiments $(n=3)$. The $\mathrm{IC}_{50}$ values of the extract and fractions for DPPH free radical scavenging and $\alpha$ glucosidase inhibitory activity were determined by Graph Pad Prism 5 software. The significant differences between the means were established by ANOVA with Bonferroni post tests and Newman-Keuls multiple comparison test. Values of $P<0.05$ were considered statistically significant.

\section{Results}

Yield

The average yield of methanol extract from solvent extraction by the maceration technique was found to be $12.63 \pm 0.98$ (as $\% w / w$ of $C$. nutans on a dry weight basis). The fractionation of methanolic extract produced the hexane, ethyl acetate, butanol, and residual aqueous fractions with average yields of $29.08 \pm 0.070,1.23 \pm 0.03,8.558 \pm 0.0305$ and $52.25 \pm 1.013$ (as the percentage of total methanol extract; the white precipitation from the butanol fraction was excluded from this study), respectively (Table 1).

\section{Total phenolic content (TPC) and total flavonoid content (TFC)}

The total phenolic content of the extract and all the fractions were, reported as gallic acid equivalents per $g$ of dried sample. The TPC of the methanol extract was $7.54 \pm 0.02 \mathrm{mg} \mathrm{GAE} / \mathrm{g}$, whereas the ethyl acetate fraction had the highest TPC $(17.403 \pm 0.025 \mathrm{mg}$ GAE/g) among all the fractions. The methanolic extract had a TFC of $16.83 \pm 0.085 \mathrm{mg}$ Rutin Equivalent/g of dried materials 
Table 1 Total yield, total phenolic content and total flavonoid content of methanol extract and its different fractions

\begin{tabular}{llll}
\hline & Yield\% & TPC $(\mathrm{mg} \mathrm{GAE} / \mathrm{g})$ & TFC $(\mathrm{mg} \mathrm{RE} / \mathrm{g})$ \\
\hline Methanol & $12.63 \pm 0.92$ & $7.54 \pm 0.52$ & $16.83 \pm 0.85$ \\
Hexane & $29.08 \pm 0.70$ & $13.31 \pm 0.36$ & $22.78 \pm 0.10$ \\
Ethyl Acetate & $1.23 \pm 0.03$ & $17.403 \pm 0.25$ & $13.29 \pm 0.04$ \\
Butanol & $8.558 \pm 0.30$ & $4.105 \pm 0.75$ & $10.04 \pm 0.56$ \\
R. Aqueous & $52.25 \pm 1.01$ & $1.32 \pm 0.02$ & $9.53 \pm 0.088$ \\
\hline
\end{tabular}

Each value in the table is represented as mean $\pm \mathrm{SD}(n=3)$

and the hexane fraction contained the maximum TFC $(22.78 \pm 0.01 \mathrm{mg} \mathrm{RE} / \mathrm{g})$ compared with all other fractions. The TPC and TFC of methanolic extract and the different fractions are presented in Table 1.

\section{DPPH free radical scavenging activity}

The DPPH free radical scavenging is a commonly used method to assess antioxidant activity in plant samples. The antioxidant activity of the samples was examined at six different concentrations (31.25, 62.5, 125, 250, 500 and $1000 \mu \mathrm{g} / \mathrm{mL})$. In this study, all the samples dose- dependently scavenged DPPH radicals, except for the residual aqueous fraction. The ethyl acetate fraction showed the highest DPPH scavenging activity, at $79.98 \pm 0.31 \%$ (IC50: $0.2691 \mathrm{mg} / \mathrm{mL}$ ) whereas the lowest scavenging ability was observed in the methanol extract, at $63.07 \pm 0.118 \%$ (IC50: $0.3302 \mathrm{mg} / \mathrm{mL}$ ). The antioxidant activity of the methanol extract and its derived fractions was ranked as follows: ethyl acetate $>$ butanol $>$ hexane $>$ methanol $>$ residual aqueous fraction. The DPPH free radical scavenging activity at different concentration of methanol extract and fractions is shown in Fig. 1.

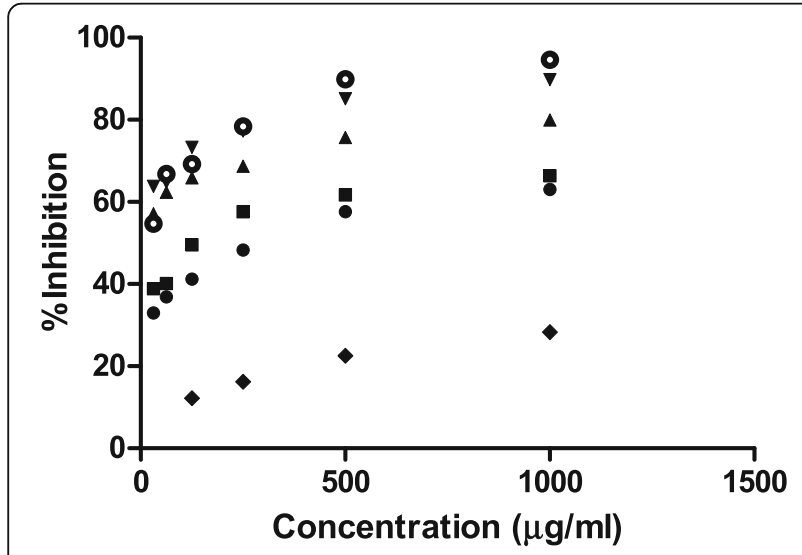

Fig. 1 DPPH Free Radical Scavenging Activity at Different Concentration of Methanol Extract and its Fractions. The $\mathrm{IC}_{50}$ values of Methanol Extract and its Hexane, EoAC, BuOH, R. aqueous Fractions are 0.3302 mg/ml, $0.1527 \mathrm{mg} / \mathrm{ml}, 0.2691 \mathrm{mg} / \mathrm{ml}, 0.2517 \mathrm{mg} / \mathrm{ml}, 0.585 \mathrm{mg} / \mathrm{ml}$ and $0.1927 \mathrm{mg} / \mathrm{ml}$, respectively. Legends: $\mathrm{MeOH}$, Hexane, $\mathbf{\Delta}$ EOAC, $\nabla \mathrm{BuOH}, \bullet \mathrm{R}$. Aqueous, $\bullet$ Quercitin
Ferric reducing antioxidant power assay

The donation of electrons by the reduction of ferric cyanide complex in the ferrous form specifies the reducing capacity of experimental samples. Essentially, this method considers the total antioxidant capacity of a sample through the oxidation-reduction potential. The methanol extract and ethyl acetate fraction exhibited the highest FRAP values of $141.89 \pm 0.874$ and $133.6 \pm 0.29 \mathrm{AAE} \mu \mathrm{g} / \mathrm{g}$ respectively (Table 2 ). The reducing power of the extract and fractions was ranked as follows: methanol > ethyl acetate $>$ butanol $>$ hexane $>$ residual aqueous.

\section{a-Glucosidase inhibitory activity}

The $\alpha$-glucosidase inhibitory activity of the methanol extract and the fractions was assessed at six different dilutions $(6.25,12.5,25,50,100$ and $200 \mu \mathrm{g} / \mathrm{mL}$ ) (Fig. 2). The highest potential $\alpha$-glucosidase inhibitory activities were found in the butanol and ethyl acetate fractions with inhibition of $72.16 \pm 1.0041 \%$ (IC50: $37.47 \mu \mathrm{g} / \mathrm{mL}$ ) and $70.76 \pm 0.4974 \%$ (IC50: $53.69 \mu \mathrm{g} / \mathrm{mL}$ ) (Table 2). The efficacy of the $\alpha$-glucosidase inhibition of the extract and various fractions was ranked as follows: butanol > ethyl acetate $>$ hexane $>$ methanol $>$ residual aqueous. The standard quercetin was used as positive control and showed a maximum $\alpha$-glucosidase inhibitory activity of $94.63 \pm 1.21 \%$ (IC50: $38.54 \mu \mathrm{g} / \mathrm{mL})$.

\section{GC Q-TOF MS analysis}

GC Q-TOF MS analysis was conducted to identify the phytoconstituents of the methanol extract and the four fractions. The spectral data were integrated with mass retention index of NIST14.L library. This study only considered those compounds with matching library scores with similarity index of $70 \%$. The biological potential of the identified compounds was compared with previously reported results (Table 3 ). The major phytochemicals were found in the methanol extract and the fractions, except residual aqueous. The identified phytochemicals belonged mainly to the classes of $\alpha$-hydroxyl

Table 2 DPPH scavenging activity, ferric reducing antioxidant power and a-Glucosidase inhibitory activity of methanol extract and its different fractions

\begin{tabular}{llll}
\hline & DPPH\% & FRAP $(\mu \mathrm{g} \mathrm{AAE} / \mathrm{g})$ & AGl\% \\
\hline Methanol & $63.07 \pm 0.11^{\mathrm{a}}$ & $141.89 \pm 3.87^{* * / *}$ & $58.21 \pm 0.8^{\mathrm{a}}$ \\
Hexane & $66.35 \pm 0.09^{\mathrm{b}}$ & $130.56 \pm 2.43^{* / *}$ & $69.94 \pm 0.81^{\mathrm{b}}$ \\
Ethyl Acetate & $79.98 \pm 0.31^{\mathrm{c}}$ & $133.6 \pm 3.29^{* / *}$ & $70.76 \pm 0.49^{\mathrm{c}}$ \\
Butanol & $78.47 \pm 0.26^{\mathrm{c}}$ & $132.76 \pm 3.72^{* * * *}$ & $72.16 \pm 1.12^{\mathrm{d}}$ \\
R. Aqueous & $28.32 \pm 0.27^{\mathrm{d}}$ & $12.11 \pm 0.31^{\mathrm{ns}}$ & $41.86 \pm 0.37^{\mathrm{e}}$ \\
\hline
\end{tabular}

Each value in the table is represented as mean \pm SD $(n=3)$. Means within each column with different letters $\left({ }^{\mathrm{a}-\mathrm{e}}\right)$ differ significantly $(p<0.05)$ according to ANOVA with Newman-keuls multiple comparison test when compared with standard. For FRAP compared total phenolic and total flavonoid content where ${ }^{*} P<0.01,{ }^{*} P<0.05,{ }^{\text {ns }} P>0.05$ according to ANOVA with Bonferroni posttests 


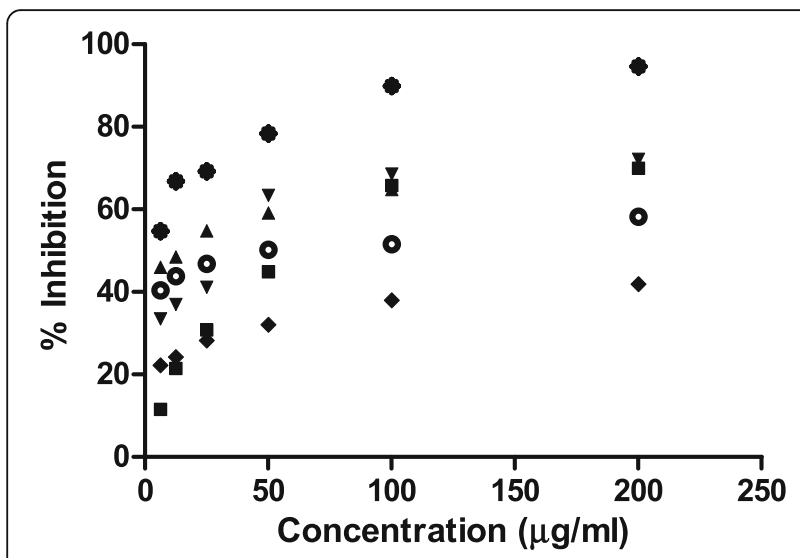

Fig. 2 a-Glucosidase Inhibitory Activity at Different Concentration of Methanol Extract and its Fractions. The $\mathrm{IC}_{50}$ values of Methanol Extract and its Hexane, EoAC, BuOH, R. aqueous Fractions are $0.06139 \mathrm{mg} / \mathrm{ml}, 0.04457 \mathrm{mg} / \mathrm{ml}, 0.05369$ mg/ml, 0.3747 mg/ml, $0.0635 \mathrm{mg} / \mathrm{ml}$ and $0.03854 \mathrm{mg} / \mathrm{ml}$, Respectively. Legends: - $\mathrm{MeOH}$, - Hexane, $\boldsymbol{\Delta}$ EoAC, $\boldsymbol{\nabla} \mathrm{BuOH}, \bullet \mathrm{R}$. Aqueous, $\boldsymbol{\bullet}$ Quercitin

acids, dicarboxylic acids, terpenes, phenolics, inositols, fatty acids, coumarins, glycosides, phytosterols, polysiloxanes and polyols. The phytochemical profiling of $C$. nutans revealed that experimental samples were abundant in the phenolic and terpenoids compounds.

\section{Discussion}

In the current study, we fractionated the crude extract of $C$. nutans using polar and non-polar solvents to obtain phytoconstituent rich biologically active standardized fractions and produced a comprehensive metabolite profiling. The average yield, TPC, and TFC of different samples are presented in Table 1. In order to achieve high quality fractionation, the purification of the extract essentially be purified to remove undesirable components could, enhance the biological activity for future pharmaceutical applications. Therefore, it is crucial to select an appropriate extraction process, as affects the characterization of secondary metabolites [32]. Plant phenolics are one of the most abundant vital group of phytochemicals and are widely known for their antioxidant and radical scavenging activity with potential impacts on human health. The phenolics are natural antioxidants which can control oxidative stress-related degenerative diseases. The adverse effects of oxidative stress have been found to be controlled by the antioxidant activities of this group of bioactive compounds. Therefore, numerous experimental studies have been designed to elucidate the antioxidant and other activities of these compounds that can inhibit certain pathological and degenerative complications [33].

As presented in Fig. 1, dose-dependent DPPH radical scavenging capacity was examined in the methanol extract and fractions, in which the standard compound (quercetin) produced the maximum antioxidant activity
(IC50: $0.1927 \mathrm{mg} / \mathrm{mL}$ ). The methanol extract, hexane and residual aqueous fractions were statistically significant when compared with quercetin (Table 2). This research work also revealed a strong agreement between the antioxidant activity of samples when measured by the TPC and TFC. Among all the fractions, the ethyl acetate fraction had the highest DPPH free radical scavenging activity and was rich in phenolic and flavonoid content $(P<0.05)$ (Table 2$)$. The TPC, TFC of butanol, and TPC of the hexane fraction also shown a significant correlation with antioxidant activity $(P<0.05)$ (Fig. 3). Hence, these findings support the antioxidant function of phenolics and are also in good agreement with previous research [34].

To determine the reducing power, the ferric reducing antioxidant power (FRAP), was studied for the methanol extract and the fractions of $C$. nutans to determine the reducing power; this provides a substantial indicator of antioxidant capacity. The presence of reducing agents in the samples is associated with the exertion of antioxidant activity by the cleavage of free radical chains through the donation of hydrogen atom. The statistically significant TPC and TFC values $(P<0.05)$, showed a positive correlation with the FRAP of methanol extract and fractions, except for the residual aqueous (Table 2). The methanol extract showed the highest reducing power, with a value of $141.89 \pm 0.87 \mu \mathrm{g}$ AAE/g followed by the ethyl acetate $(133.6 \pm 0.29)$, butanol $(132.76 \pm 0.72)$, hexane $(130.56 \pm 0.43)$ fractions.

An effective approach for the management of carbohydrate metabolic disorders, including diabetes mellitus type II is the inhibition of the $\alpha$-glucosidase enzyme [35]. A delay in the digestion of carbohydrate plays an important role in the control of postprandial hyperglycemia, hyper insulinemia and decreases the risk of cardiovascular disease [36]. The $\alpha$-glucosidase inhibitory activity of the methanol extract and fractions were significantly to the standard compound (Table 2).

Natural bioactive compounds regulate blood glucose level through obstructing the degradation of polysaccharides [37]. Plant phenolics are natural $\alpha$-glucosidase inhibitors because they inhibit intestinal carbohydrate digesting enzymes owing to their protein-binding capability [38]. Recent researchers have reported the $\alpha$-glucosidase inhibitory activity of numerous flavonoid compounds [39]. As shown in Fig. 2, the $\alpha$-glucosidase inhibitory activity of methanol extract and the obtained fractions were evaluated at different concentrations: the strongest inhibitory concentration (IC50 $37.47 \mu \mathrm{g} / \mathrm{mL}$ ) was found in the butanol fraction compared with the standard compound. A multiple range test, between the extract, fractions and positive control is shown in Table 2; the extract and fractions were significantly different from the control $(P<0.05)$.

The current study also revealed a significant $(P<0.05)$ correlation between the TPC and TFC with an $\alpha$-glucosidase 
Table 3 Identified metabolites in methanol extract and its different fractions

\begin{tabular}{|c|c|c|c|c|c|}
\hline$\overline{\mathrm{MeOH}}$ & Mass & Formula (DB) & Score (Lib) & $\mathrm{m} / \mathrm{z}$ & RT \\
\hline Glyceric acid ${ }^{\text {rq }}$ & 322.145 & $\mathrm{C}_{12} \mathrm{H}_{30} \mathrm{O}_{4}$ & 82.1 & 73.03153 & 22.04 \\
\hline Malic acid hex, ra & 350.14 & $\mathrm{C}_{13} \mathrm{H}_{30} \mathrm{O}$ & 82.63 & 73.03153 & 31.411 \\
\hline Erythritol hex, bu., rq & 410.216 & $\mathrm{C}_{16} \mathrm{H}_{42} \mathrm{O}_{4}$ & 83.96 & 73.03153 & 33.044 \\
\hline Ribitol hex & 512.266 & $\mathrm{C}_{20} \mathrm{H}_{52} \mathrm{O}_{5}$ & 90.44 & 73.03153 & 49.243 \\
\hline Neophytadiene & 278.297 & $\mathrm{C}_{20} \mathrm{H}_{38}$ & 81.5 & 67.0393 & 53.357 \\
\hline Mannitol bu & 614.316 & $\mathrm{C}_{24} \mathrm{H}_{62} \mathrm{O}_{6}$ & 86.43 & 73.03153 & 56.957 \\
\hline Gluconic acid & 628.295 & $\mathrm{C}_{24} \mathrm{H}_{60} \mathrm{O}_{7}$ & 72.71 & 73.03153 & 58.972 \\
\hline Palmitic acid ${ }^{\text {ra }}$ & 328.28 & $\mathrm{C}_{19} \mathrm{H}_{40} \mathrm{O}_{2}$ & 75.99 & 117.0168 & 59.131 \\
\hline Rhamnose ea., bu., rq & 452.227 & $\mathrm{C}_{18} \mathrm{H}_{44} \mathrm{O}_{5}$ & 71.07 & 73.03153 & 59.918 \\
\hline Myo-Inositol hex, ea., bu & 612.301 & $\mathrm{C}_{24} \mathrm{H}_{60} \mathrm{O}_{6}$ & 81.27 & 73.03153 & 61.069 \\
\hline Oleic Acid hex & 354.295 & $\mathrm{C}_{21} \mathrm{H}_{42} \mathrm{O}_{2}$ & 74.58 & 75.01034 & 63.292 \\
\hline Stearic acid hex, ea., bu., rq & 356.311 & $\mathrm{C}_{21} \mathrm{H}_{44} \mathrm{O}_{2}$ & 75.89 & 117.0168 & 63.921 \\
\hline 1-Monopalmitin hex, ea., bu., rq & 474.356 & $\mathrm{C}_{25} \mathrm{H}_{54} \mathrm{O}_{4}$ & 86.25 & 371.2661 & 76.818 \\
\hline Hexane & Mass & Formula (DB) & Score (Lib) & $\mathrm{m} / \mathrm{z}$ & RT \\
\hline Glycolic acid ea., bu., rq & 220.095 & $\mathrm{C}_{8} \mathrm{H}_{20} \mathrm{O}_{3}$ & 78.81 & 147.0445 & 8.457 \\
\hline Glycerol hex, bu & 308.166 & $\mathrm{C}_{12} \mathrm{H}_{32} \mathrm{O}_{3}$ & 86.8 & 73.03193 & 18.785 \\
\hline Myristic acid & 300.248 & $\mathrm{C}_{17} \mathrm{H}_{36} \mathrm{O}_{2}$ & 77.37 & 117.0175 & 53.071 \\
\hline Hexadecanoic acid bu & 270.256 & $\mathrm{C}_{17} \mathrm{H}_{34} \mathrm{O}_{2}$ & 80.98 & 87.02704 & 55.509 \\
\hline Cyclononasiloxane ea., bu & 666.169 & $\mathrm{C}_{18} \mathrm{H}_{54} \mathrm{O}_{9}$ & 78.42 & 73.03193 & 64.886 \\
\hline Squalene & 410.391 & $\mathrm{C}_{30} \mathrm{H}_{50}$ & 76.25 & 81.05419 & 83.616 \\
\hline Sulfurous acid & 376.301 & $\mathrm{C}_{21} \mathrm{H}_{44} \mathrm{O}_{3}$ & 79.63 & 57.05663 & 85.537 \\
\hline$\beta$-Tocopherol & 488.405 & $\mathrm{C}_{31} \mathrm{H}_{56} \mathrm{O}_{2}$ & 78.3 & 488.3697 & 87.803 \\
\hline 1-Tetracosanol & 426.426 & $\mathrm{C}_{27} \mathrm{H}_{58} \mathrm{O}$ & 74.64 & 411.3688 & 87.824 \\
\hline Y-Tocopherol & 488.405 & $\mathrm{C}_{31} \mathrm{H}_{56} \mathrm{O}_{2}$ & 76.32 & 73.03193 & 88.004 \\
\hline Lupeol & 426.386 & $\mathrm{C}_{30} \mathrm{H}_{50} \mathrm{O}$ & 78.1 & 189.1404 & 98.854 \\
\hline EoAC & Mass & Formula (DB) & Score (Lib) & $\mathrm{m} / \mathrm{z}$ & RT \\
\hline Lactic Acid ${ }^{\text {rq }}$ & 234.111 & $\mathrm{C}_{9} \mathrm{H}_{22} \mathrm{O}_{3}$ & 70.76 & 73.03193 & 7.867 \\
\hline Hexanoic acid & 188.123 & $\mathrm{C}_{9} \mathrm{H}_{20} \mathrm{O}_{2}$ & 82.18 & 73.03193 & 8.127 \\
\hline Oxalic acid & 234.074 & $\mathrm{C}_{8} \mathrm{H}_{18} \mathrm{O}_{4}$ & 74.24 & 147.0437 & 11.408 \\
\hline Benzoic acid & 194.076 & $\mathrm{C}_{10} \mathrm{H}_{14} \mathrm{O}_{2}$ & 89.19 & 135.0956 & 16.142 \\
\hline Benzeneacetic acid & 208.092 & $\mathrm{C}_{11} \mathrm{H}_{16} \mathrm{O}_{2}$ & 82.37 & 73.03193 & 19.06 \\
\hline Tyrosol & 282.147 & $\mathrm{C}_{14} \mathrm{H}_{26} \mathrm{O}_{2}$ & 83.45 & 179.063 & 35.281 \\
\hline Arabinitol bu., ra & 512.266 & $\mathrm{C}_{20} \mathrm{H}_{52} \mathrm{O}_{5}$ & 87.01 & 73.03193 & 49.249 \\
\hline Vanillic acid & 312.121 & $\mathrm{C}_{14} \mathrm{H}_{24} \mathrm{O}_{4}$ & 81.66 & 297.1034 & 49.77 \\
\hline 4-Coumaric acid & 308.126 & $\mathrm{C}_{15} \mathrm{H}_{24} \mathrm{O}_{3}$ & 81.65 & 293.1079 & 50.764 \\
\hline p-Coumaric alcohol & 294.147 & $\mathrm{C}_{15} \mathrm{H}_{26} \mathrm{O}_{2}$ & 75.26 & 73.03193 & 51.005 \\
\hline Azelaic acid & 332.184 & $\mathrm{C}_{15} \mathrm{H}_{32} \mathrm{O}_{4}$ & 85.4 & 73.03193 & 51.378 \\
\hline Tryptophol & 305.163 & $\mathrm{C}_{16} \mathrm{H}_{27} \mathrm{NO}$ & 73.32 & 202.1438 & 54.561 \\
\hline Syringic acid & 342.132 & $\mathrm{C}_{15} \mathrm{H}_{26} \mathrm{O}_{5}$ & 76.23 & 327.0037 & 55.145 \\
\hline Heptasiloxane & 532.184 & $\mathrm{C}_{16} \mathrm{H}_{48} \mathrm{O}_{6}$ & 70.08 & 355.0375 & 87.993 \\
\hline D-Xylose bu & 438.211 & $\mathrm{C}_{17} \mathrm{H}_{42} \mathrm{O}_{5}$ & 74.23 & 191.0664 & 88.537 \\
\hline
\end{tabular}


Table 3 Identified metabolites in methanol extract and its different fractions (Continued)

\begin{tabular}{|c|c|c|c|c|c|}
\hline $\mathrm{BuOH}$ & Mass & Formula (DB) & Score (Lib) & $m / z$ & RT \\
\hline Propylene glycol & 220.131 & $\mathrm{C}_{9} \mathrm{H}_{24} \mathrm{O}_{2}$ & 72.85 & 73.03256 & 13.928 \\
\hline Dulcitol & 614.316 & $\mathrm{C}_{24} \mathrm{H}_{62} \mathrm{O}_{6}$ & 73.74 & 73.03256 & 56.96 \\
\hline Octadecanoic acid & 284.272 & $\mathrm{C}_{18} \mathrm{H}_{36} \mathrm{O}_{2}$ & 71.73 & 87.02775 & 62.021 \\
\hline Residual Aqueous & Mass & Formula (DB) & Score (Lib) & $m / z$ & RT \\
\hline Butanedioic acid & 262.106 & $\mathrm{C}_{10} \mathrm{H}_{22} \mathrm{O}_{4}$ & 78.34 & 147.0448 & 20.507 \\
\hline Xylitol & 512.266 & $\mathrm{C}_{20} \mathrm{H}_{52} \mathrm{O}_{5}$ & 75.32 & 73.0321 & 49.24 \\
\hline
\end{tabular}

Subscript with hex-hexane fraction, ea.- ethyl acetate fraction, bu.-butanol fraction, rq-residual aqueous fraction represents the identified compound in that fraction

inhibitory activity of the samples (Fig. 4). The higher concentration phenolics, flavonoids and higher antioxidant activity, resulted in a higher enzyme inhibitory capacity (Table 2). The results from the current study are in good agreement with other research works, which have reported the ability of phenolic rich extracts that exhibited a high antioxidant and $\alpha$-glucosidase inhibitory effect [40]. Furthermore, these results revealed a direct correlation between antioxidant activity and $\alpha$-glucosidase inhibitory activity. Butanol, ethyl acetate and hexane fractions revealed similar $\alpha$-glucosidase inhibitory activities of 72.16 $\pm 1.0041 \%, 70.76 \pm 0.4974 \%$ and $69.94 \pm 0.8115 \%$ whereas the methanol extract showed moderate inhibitory activity $58.21 \pm 0.08 \%$. The butanol fraction had significantly higher $(P<0.05) \alpha$-glucosidase inhibitory activity, with an IC50 value of $37.47 \mu \mathrm{g} / \mathrm{mL}$, which is close to the standard quercetin compound (IC50: $38.54 \mu \mathrm{g} / \mathrm{mL}$ ). The higher phytochemical content and antioxidant activity significantly influenced the $\alpha$-glucosidase inhibitory activity of the samples $(P<0.05)$.

The most abundant identified phytoconstituents were neophytadiene, squalene, lupeol, tocopherols, vanillic acid,

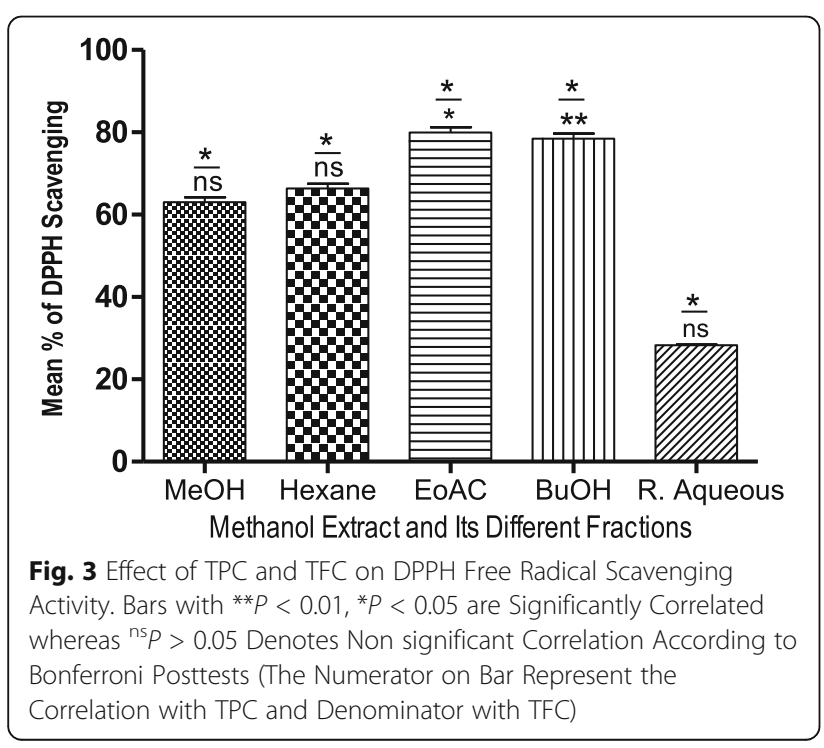

syringic acid, myo-inositol, glycolic acid, butanedioic acid, 4-coumaric acid, and stigmasterol. Extensive literature searches documented that the identified compounds were responsible for various biological activities, including antioxidants, antidiabetic, and anti-inflammatory chemotherapeutic agents [41]. The structural orientation of the polyphenolic compounds owing to the lactones/quinones or 4-oxo-pyrane moiety responsible for the digestive enzyme inhibitory activity [42]. It was also reported that phenolic compounds help to reduce the intestinal digestive enzymes and were able to oxidize the body fat owing to their thermogenic properties [43], whereas the terpenes and terpenoids class of compounds can act as antihyperglycemic agents [44].

\section{Conclusion}

The methanol extract of $C$. nutans and the obtained solvent fractions exhibited a significant range of biological activities. The ethyl acetate and butanol fractions of the methanol extract had the highest antioxidant and $\alpha$-glucosidase inhibitory activity which showed a significant correlation with the total phenolic and total flavonoid contents of the fractions.

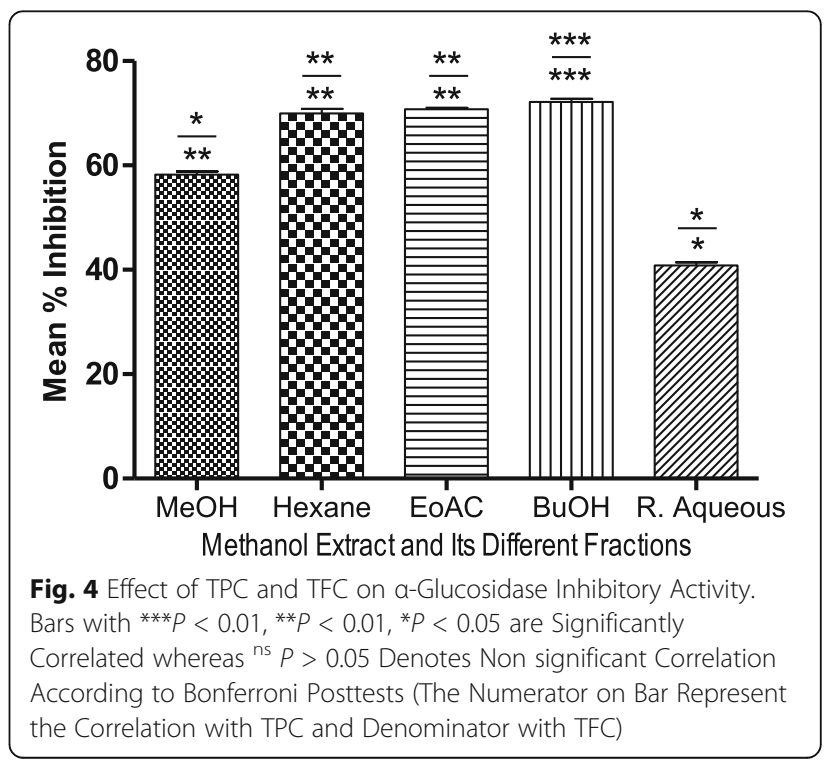


In addition, there was a strong correlation of the antioxidant activity with the $\alpha$-glucosidase inhibitory potency of different samples. GC Q-TOF MS analysis showed that the presence of major phytoconstituents might be responsible for the potential antioxidant and $\alpha$-glucosidase inhibitory activities of C. nutans extract and fractions. However, further toxicological study of the antioxidant rich fractions is necessary to verify their suitability for future pharmaceutical applications.

\section{Abbreviations}

CN: Clinacanthus nutans; GC Q-TOF-MS: Gas Chromatography Quadrupole Time of Flight Mass Spectroscopy; DPPH: 2, 2-dyphenyl-1-picrylhydrazyl; TPC: Total Phenolic Content; TFC: Total Flavonoid Content; DMSO: Dimethy sulfoxide; FRAP: Ferric Reducing Antioxidant Power; TPTZ: 2,4,6-Tripyridyl-sTriazine; AAE: Ascorbic Acid Equivalent; ANOVA: Analysis of Variance

\section{Acknowledgement}

We would like to acknowledge the Malaysian International Scholarship, Ministry of Higher Education, Malaysia. We extend our appreciation to the International Scientific Partnership Program ISPP at King Saud University, Riyadh, Saudi Arabia, for funding this research work (ISPP\# 0026).

The study was also supported partially by the special postdoc program under Research Initiative Grant Scheme (RIGS16-397-0561).

\section{Funding}

This study is supported and financed by the research grant of Ministry of Higher Education Malaysia through International Islamic University of Malaysia.

\section{Availability of data and materials}

Publicly available repositories

\section{Authors' contributions}

Study design, experimental and analytical work done by MA under supervision of MZI, co-supervision of SF, AK. Article written by MA and revised by KG, HA, RM. Data interpretation and assistance provided by AM, BM. Special assistance by PV. All authors read and approved the final manuscript.

\section{Competing interest}

The authors declare that they have no competing interests.

\section{Consent for publication}

Not applicable

\section{Ethics approval and consent to participate}

Not applicable

\section{Author details \\ ${ }^{1}$ Faculty of Pharmacy, International Islamic University Malaysia (IIUM), Kuantan Campus, 25200 Kuantan, Pahang, Malaysia. ${ }^{2}$ Department of Food Science and Nutrition, King Saud University, Riyadh 11451, Saudi Arabia. ${ }^{3}$ Faculty of Science, International Islamic University Malaysia (IIUM), Kuantan Campus, 25200 Kuantan, Pahang, Malaysia. ${ }^{4}$ Institute of Tropical Agriculture, University Putra Malaysia, 43400 UPM, Serdang, Selangor Darul Ehsan, Malaysia. ${ }^{5}$ Faculty of Agricultural Engineering and Technology, Bangladesh Agricultural University, Mymensingh, Bangladesh. ${ }^{6}$ Department of Pharmaceutical Technology and Industry, Faculty of Pharmacy, Cyberjaya University College of Medical Science, No. 3410, Jalan Teknokrat 3, Cyber 4, 63000 Cyberjaya, Selangor Darul Ehsan, Malaysia.}

Received: 25 August 2016 Accepted: 15 March 2017

Published online: 31 March 2017

\section{References}

1. Gomathi D, Ravikumar G, Kalaiselvi M, Vidya B, Uma C. In vitro free radical scavenging activity of ethanolic extract of the whole plant of Evolvulus alsinoides (L.). Chin J Integr Med. 2015;21:453-8.

2. Ghasemzadeh A, Hawa ZEJ. Antioxidant potential and anticancer activity of young ginger (Zingiber officinale Roscoe) grown under different $\mathrm{CO}_{2}$ concentration. J Med Plants Res. 2011;5:3247-55.
3. Ghasemzadeh A, Hawa ZEJ. Profiling of phenolic compounds and their antioxidant and anticancer activity in pandan (Pandanus amanyllifolius Roxb.) extracts from different locations of Malaysia. BMC Complement Altern Med. 2013;13:341.

4. Lobo V, Patil A, Phatak A, Chandra N. Free radicals, antioxidants and functional foods: Impact on human health. Pharmacogn Rev. 2010;4:118-26.

5. McCord JM. The evolution of free radicals and oxidative stress. Am J Med. 2000;108:652-9.

6. Changwei A. Anping Li, Elzaawely, AA, Xuan TD, Shinkichi T. Evaluation of antioxidant and antibacterial activities of Ficus microcarpa L. fil. Extract. Food Control. 2008;19:940-8.

7. Cai YZ, Sun M, Corke H. Antioxidant activity of betalains from plants of the Amaranthaceae. J Agric Food Chem. 2003;51:2288-94.

8. Tapas AR, Sakarkar DM, Kakde RB. Flavonoids as nutraceuticals: a review. Trop J Pharm Res. 2008;7:1089-99.

9. Aiyegoro OA, Okoh Al. Preliminary phytochemical screening and in vitro antioxidant activities of the aqueous extract of Helichrysum longifolium DC BMC Complement Alternat Med. 2010;10:21.

10. Attele AS, Zhou YP, Xie JT. Antidiabetic effects of Panax ginseng berry extract and the identification of an effective component. Diabetes. 2002;51: 1851-8.

11. Laakso M. Insulin resistance and its impact on the approach to therapy of type 2 diabetes. Int J Clin Pract. 2001;121:8-12.

12. Satyanarayana T, Katyayani BM, Latha HE. Hypoglycemic and antihyperglycemic effect of alcoholic extract of Euphorbia leucophylla. Phcog Mag. 2006;2:244-53.

13. De Melo Junior EJM, Raposo MJ, Lisboa Neto JA. Medicinal plants in the healing of dry socket in rats: Microbiological and microscopic analysis. Phytomedicine. 2002;9:109-16.

14. Kim YM, Jeong YK, Wang MH, Lee WY, Rhee HI. Inhibitory effect of pine extract on a-glucosidase activity and postprandial hyperglycemia. Nutrition. 2005;21:756-61.

15. Narkhede MB, Ajimire PV, Wagh AE, Mohan M, Shivashanmugam AT. In vitro antidiabetic activity of Caesalpina digyna (R.) methanol root extract. Asian J Plant Sci. 2011:1:101-6.

16. Franco OL, Rigden DJ, Melo FR, Grosside SMF. Plant a-amylase inhibitors and their interaction with insect alpha-amylases. Eur J Biochem. 2002;269: $397-412$.

17. Yin Z, Zhang W, Feng F, Zhang Y, Kang W. a-Glucosidase inhibitors isolated from medicinal plants. Food Sci Human Wellness. 2014;3:136-74.

18. Tuntiwachwuttikul P, Pootaeng-on Y, Pansa P, Srisanpang T, Taylor WC. Sulfur-containing compounds from Clinacanthus siamensis. Chem Pharm Bulle. 2003;51:1423-5.

19. Sakdarat S, Shuyprom A, Dechatiwongse NA, Waterman PG, Karagianis G. Chemical composition investigation of Clinacanthus nutans Lindau leaves. Thai J Phytopharmaco. 2006;13:13-24.

20. Charuwichitratana S, Wongrattanapasson N, Timpatanapong P, Bunjob M. Herpes zoster: treatment with Clinacanthus nutans cream. Int I Dermatol. 1996;35:665-6

21. Janwitayanuchit WSK, Patarapanich C, Pummangura S, Lipipun V, Vilaivan T. Synthesis and anti-herpes simplex viral activity of monoglycosyl diglycerides. Phytochemistry. 2003;64:1253-64.

22. Sakdarat S, Shuyprom A, Pientong C, Ekalaksananan T, Thongchai S. Bioactive constituents from the leaves of Clinacanthus nutans Lindau. Bioorg Med Chem. 2009;17:1857-60

23. Yoosook C, Panpisutchai Y, Chaichana S, Santisuk T, Reutrakul V. Evaluation of anti-HSV-2 activities of Barleria lupulina and Clinacanthus nutans. J Ethnopharmacol. 1999;67:179-87.

24. Zhang Q, Zhang JZ, Shen JK, Silva A, Dennis DA, Barrow CJ. A simple 96well microplate method for estimation of total polyphenol content in seaweeds. J Appl Phycol. 2006;18:445-50.

25. Lin JY, Tang CY. Determination of total phenolic and flavonoid contents in selected fruits and vegetables, as well as their stimulatory effects on mouse splenocyte proliferation. Food Chem. 2007;101:140-7.

26. Fukumoto LR, Mazza G. Assessing antioxidant and pro-oxidant activities of phenolic compounds. J Agr Food Chem. 2000;48:3597-604

27. Szydlowska-Czerniak A, Dianoczki C, Recseg K, Karlovits G, Szlyk E. Determination of antioxidant capacities of vegetable oils by ferric-ion spectrophotometric methods. Talanta. 2008;76:899-905.

28. Collins RA, Ng TB, Fong WP, Wan CC, Yeung HW. Inhibition of glycohydrolase enzymes by aqueous extracts of Chinese medicinal herbs in a microplate format. Biochem Mol Biol Int. 1997;42:1163-9. 
29. Subramanian R, Asmawi MZ, Sadikun A. In vitro alpha-glucosidase and alpha-amylase enzyme inhibitory effects of Andrographis paniculata extract and andrographolide. Acta Biochim Pol. 2008;55:391-8.

30. Deutschländer MS, Van De Venter M, Roux S, Louw J, Lall N. Hypoglycaemic activity of four plant extracts traditionally used in South Africa for diabetes. J Ethnopharmacol. 2009;124:619-24.

31. Robinson AR, Gheneim R, Kozak RA, Ellis DD, Mansfield SD. The potential of metabolite profiling as a selection tool for genotype discrimination in Populus. J Exp Bot. 2005;56:2807-19.

32. Smith RM. Before the injection- modern methods of sample preparation for separation techniques. J Chromatogra A. 2003;1000:3-27.

33. Floris AL, Peter LL, Reinier PA, Elov HL, Guy ER, Chris W. Glucosidase inhibitors for patients with type 2 diabetes. Diab Care. 2005;28:154-63.

34. Misra S, Pandeya KB, Tiwari AK, Ali AZ, Saradamani T, Agawane SB, Madhusudana K. Antihyperglycemic, alpha-glucosidase inhibitory and DPPH free radical scavenging activity of 5-bromosalicylaldehyde and schiff bases. Med Chem Res. 2010:3:1-7.

35. Olubomehin OO, Abo KA, Ajaiyeoba EO. Alpha-amylase inhibitory activity of two Anthocleista species and in vivo rat model antidiabetic activities of Anthocleista djalonensis extracts and fractions. J Ethnopharmacol. 2013;146:811-4.

36. Griffiths DW, Moseley $\mathrm{G}$. The effect of diets containing field beans of high or low polyphenolic content on the activity of digestive enzymes in the intestines of rats. J Sci Food Agric. 1980;31:255-9.

37. Zhang HY, Yan L. Research progress in anti-microbial of flavonoids. Anti Infect Pharm. 2009;6:92-5.

38. Küpeli E, Aslan M, Gürbüz I, Yesilada E. Evaluation of in vivo biological activity profile of isoorientin. Z Naturforsch. 2004;59:787-90.

39. Fornari T, Vicente G, Vàzquez E, Garcìa-Risco MR, Reglero G. Isolation of essential oil from different plants and herbs by supercritical fluid extraction. J Chromatogr A. 2012;1250:34-48.

40. Rodríguez-Cerdeira C, Sánchez-Blanco E. Glycolic Acid 15\% Plus Salicylic Acid 2\% A new therapeutic pearl for Facial Flat Warts. J Clin Aesthet Dermatol. 2011:4:62-4.

41. Yin-Yin O, leva S. Gallic acid and gallic acid derivatives: effects on drug metabolizing enzymes. Curr Drug Metab. 2003:4:241-8.

42. Funke I, Melzig MF. Effect of different phenolic compounds on alphaamylase activity: screening by microplate-reader based kinetic assay. Pharmazie. 2005;60:796-7.

43. Alterio AA, Fava DAF, Navarro F. Interaction of the daily ingestion of green tea (Camella sinensis) in the cellular metabolism and the adipose cell promoting emagrecimento. Rev Bras Obes Nut Emag. 2007;1:27-37.

44. Tundis R, Loizzo MR, Menichini F. Natural products as alpha-amylase and alpha-glucosidase inhibitors and their hypoglycaemic potential in the treatment of diabetes: an update. Mini Rev Med Chem. 2010;10:315-31.

\section{Submit your next manuscript to BioMed Central and we will help you at every step:}

- We accept pre-submission inquiries

- Our selector tool helps you to find the most relevant journal

- We provide round the clock customer support

- Convenient online submission

- Thorough peer review

- Inclusion in PubMed and all major indexing services

- Maximum visibility for your research

Submit your manuscript at www.biomedcentral.com/submit 